\title{
CONVERGENCE IN MEASURE OF FEJÉR MEANS OF TWO PARAMETER CONJUGATE WALSH TRANSFORMS
}

\author{
Ushangi GoginaVA* AND SAlEm Ben SAID
}

Abstract. Weisz proved-among others - that for $f \in L \log L$ the Fejér means $\widetilde{\sigma}_{n, m}^{(t, u)}$ of conjugate transform of two-parameter Walsh-Fourier series a. e. converges to $f^{(t, u)}$. The main aim of this paper is to prove that for any Orlicz space, which is not a subspace of $L \log L$, the set of functions for which Walsh-Fejér Means of two parameter Conjugate Transforms converge in measure is of first Baire category.

Mathematics subject classification (2010): 42C10.

Keywords and phrases: Double Walsh-Fourier series, conjugate transform, convergence in measure.

\section{REFERENCES}

[1] A. Garsia, Topics in almost everywhere convergence. Lectures in Advanced Mathematics, 4 Markham Publishing Co., Chicago, 1970.

[2] G. Gát, U. Goginava And G. Tkebuchava, Convergence in measure of logarithmic means of double Walsh-Fourier series, Georgian Math. J. 12, 4 (2005), 607-618.

[3] G. Gát, U. Goginava And G. Tkebuchava, Convergence in measure of logarithmic means of quadratical partial sums of double Walsh-Fourier series, J. Math. Anal. Appl. 323, 1 (2006), 535549.

[4] G. GÁt, On the divergence of the $(C, 1)$ means of double Walsh-Fourier series, Proc. Amer. Math. Soc. 128, 6 (2000), 1711-1720.

[5] R. Gets ADZE, On the divergence in measure of multiple Fourier seties, Some problems of functions theory 4, 1 (1988), 84-117.

[6] B. I. Golubov, A. V. EFimov And V. A. Skvortsov, Series and transformations of Walsh, Nauka, 1987 (Russian); English transl.: Kluwer Acad. publ, Moscow, 1991.

[7] S. A. Konjagin, On subsequences of partial Fourier-Walsh series, Mat. Notes, 54, 4 (1993), 69-75.

[8] A. N. Kolmogorov, Sur les functions harmoniques conjugees and les series de Fouries, Fund. Math. 7, 1 (1925), 23-28.

[9] G. Morgenthaller, Walsh-Fourier series, Trans. Amer. Math. Soc. 84, 2 (1957), 472-507.

[10] F. MörICZ, F. SCHIPP AND W. R. WADE, Cesàro summability of double Walsh-Fourier series, Trans Amer. Math. Soc. 329, 1 (1992), 131-140.

[11] A. Paley, A remarkable series of orthogonal functions, Proc. London Math. Soc. 3, 4 (1932), $241-$ 279.

[12] F. Schipp, W. R. WAde, P. Simon AND J. PÁL, Walsh series: an introduction to dyadic harmonic analysis, Adam Hilger, Bristol and New York, 1990.

[13] M. A. KRasnosel'skiI AND YA. B. RUTiCKII, Convex functions and Orlicz space (English translation), P. Noordhoff Ltd., Groningen, 1961.

[14] G. Tkebuchava, On multiple Fourier, Fourier-Walsh and Fourier-Haar series in nonreflexive separable Orlicz space, Bull. Georg. Acad. Sci. 149, 2 (1994), 1-3.

[15] C. WATARY, On generalized Fourier-Walsh series, Tōhoku Math. J. vol 10, 3 (1968), 211-241.

[16] F. WeIsZ, Martingale Hardy spaces and their Applications in Fourier analysis, Springer, BerlinHeidelberg-New York, 1994. 
[17] F. WEISZ, Summability of multi-dimensional Fourier series and Hardy space, Kluwer Academic, Dordrecht, 2002.

[18] F. WEISZ, The maximal $(C, \alpha, \beta)$ operator of two-parameter Walsh-Fourier series, J. Fourier Anal. Appl. 6, 4 (2000), 389-401.

[19] L. V. ZhizhiashVili, Some problems of multidimensional harmonic analysis, TGU, Tbilisi, 1996. 